\title{
Characterization of Clinical and Immune Responses in an Experimental Chronic Autoimmune Uveitis Model
}

\author{
Nai-Wen Fan, ${ }^{* \dagger \ddagger}$ Joy Li, ${ }^{\star}$ Sharad K. Mittal, ${ }^{*}$ William Foulsham, ${ }^{*}$ Elsayed Elbasiony, ${ }^{*}$ Rachel M. Huckfeldt, ${ }^{\S}$ Sunil K. Chauhan, ${ }^{*}$
} and Yihe Chen*

From the Department of Ophthalmology, * Schepens Eye Research Institute of Massachusetts Eye and Ear, and the Department of Ophthalmology, ${ }^{\S}$ Massachusetts Eye and Ear, Harvard Medical School, Boston, Massachusetts; the Department of Ophthalmology, ${ }^{\dagger}$ Taipei Veterans General Hospital, Taipei, Taiwan; and the Faculty of Medicine,$^{\ddagger}$ National Yang-Ming University School of Medicine, Taipei, Taiwan

\author{
Accepted for publication \\ September 4, 2020. \\ Address correspondence to \\ Yihe Chen, M.D., Schepens \\ Eye Research Institute of Mas- \\ sachusetts Eye and Ear, 20 \\ Staniford St., Boston, MA \\ 02114. E-mail: yihe_chen@ \\ meei.harvard.edu.
}

\begin{abstract}
Autoimmune uveitis is a sight-threatening intraocular inflammatory disease. For $>30$ years, the mouse model of experimental autoimmune uveitis has been employed to investigate disease mechanisms and test immunotherapeutic approaches. However, inflammation in this model is self-limited, and does not replicate the chronic, insidious nature prevalent in the human disease. Herein, a robust and reliable model of chronic autoimmune uveitis was developed and characterized in two strains of wild-type mice by modifying interphotoreceptor retinoid-binding protein dose and peptide fragments from conventional experimental autoimmune uveitis models. In both of these murine strains, immunization with our modified protocols resulted in a slowly progressive uveitis, with retinal scars and atrophy observed in the chronic stage by fundoscopy. Optical coherence tomography demonstrated decreased retinal thickness in chronic autoimmune uveitis mice, and electroretinography showed significantly reduced amplitudes of dark-adapted a- and b-waves and light-adapted b-waves. Histologic examination revealed prominent choroiditis with extensive retinal damage. Flow cytometry analysis showed substantially increased numbers of $\mathrm{CD} 44^{\mathrm{hi}} \mathrm{IL}-17^{+} \mathrm{IFN}-\gamma^{-}$memory T-helper 17 (Th17) cells in the retina, cervical lymph nodes, inguinal lymph nodes, and spleen. These data establish new modified protocols for inducing chronic uveitis in wild-type mice, and demonstrate a predominant memory Th17 cell response, suggesting an important role for memory Th17 cells in driving chronic inflammation in autoimmune uveitis. (Am J Pathol 2021, 191: 425-437; https://doi.org/10.1016/j.ajpath.2020.09.004)
\end{abstract}

Uveitis is a sight-threatening inflammatory condition of the uveal tract of the eye, comprising the iris, ciliary body, and choroid. ${ }^{1}$ Responsible for an estimated 30,000 new cases of legal blindness each year in the United States, uveitis and its complications cause approximately $10 \%$ of irreversible vision loss. ${ }^{2-5}$ The socioeconomic impact of uveitis is notable because as blindness frequently occurs in individuals of working age. ${ }^{6}$ In contrast to acute uveitis, which often resolves after a short course of topical corticosteroids, chronic uveitis is characterized by active inflammation that persists for at least several months, and frequently years. The persistent inflammation and its long-term requirement for corticosteroids lead to a high incidence of complications that endanger vision, including glaucoma, cataract, optic disc atrophy, and chorioretinal scars.

Experimental animal models have been used to recapitulate the clinical phenotype of uveitis, and have led to significant advances in our understanding of the cellular and molecular mechanisms that cause autoimmune uveitis. ${ }^{8}$ For

\footnotetext{
Supported by NIH grants EY024602 (S.K.C.) and P30EY003790 (Massachusetts Eye and Ear); and the Yin Shu-Tien Foundation through the Taipei Veterans General Hospital-National Yang-Ming University Excellent Physician Scientists Cultivation Program (N.-W.F. ).

N.-W.F. and J.L. contributed equally to this work.

Disclosure: None declared.
} 
example, these studies have established the critical roles of pathogenic effector T-helper 1 (Th1) and T-helper 17 (Th17) cells in the immunopathogenesis of uveitis. ${ }^{8-10}$ However, most preclinical research on autoimmune uveitis has investigated acute disease, but not the development and maintenance of chronic autoimmune uveitis (CAU). ${ }^{11}$ This is because, in the widely used mouse experimental autoimmune uveitis (EAU) model, disease peaks in the first 2 to 3 weeks after immunization before resolving spontaneously. ${ }^{12-15}$ Yet, as discussed, it is CAU that is associated with the greatest morbidity and risk of sight-threatening complications in the clinic, underscoring a pressing need for the development of a chronic uveitis animal model. ${ }^{7}$

In the present study, a reliable murine model of chronic experimental autoimmune uveitis was established and characterized in two wild-type mouse strains, which exhibit clinical features consistent with noninfectious uveitis observed in humans. Furthermore, in contrast to early acute uveitis in which the immune response is characterized by both effector Th1 and effector Th17 cells, we demonstrate that CAU is primarily characterized by a robust memory Th17 response in both the retina and peripheral lymphoid compartments.

\section{Materials and Methods}

\section{Animals}

Wild-type B10.RIII mice (The Jackson Laboratory, Bar Harbor, ME) and C57BL/6 mice (Charles River Laboratories, Wilmington, MA) at 8 to 10 weeks of age were used for this study. All animal experiments were approved by the Schepens Eye Research Institute Animal Care and Use Committee and adhered to the Association for Research in Vision and Ophthalmology Statement for the Use of Animals in Ophthalmic and Vision Research.

\section{Induction of Chronic Autoimmune Uveitis}

CAU was induced in mice using a protocol modified from previous studies. ${ }^{10,15-17}$ In brief, B10.RIII mice were immunized with $50 \mu \mathrm{g}$ human interphotoreceptor retinoid-binding protein (IRBP) peptide (residues 161 to 180; AnaSpec, Fremont, CA) emulsified in $0.2 \mathrm{~mL}$ complete Freund adjuvant (CFA; containing $2.5 \mathrm{mg} / \mathrm{mL}$ Mycobacterium tuberculosis strain H37RA; Difco; Sigma, St. Louis, MO). C57BL/6 mice were immunized with $150 \mu \mathrm{g}$ human IRBP peptide (residues 161 to 180 ) and $300 \mu \mathrm{g}$ human IRBP peptide (residues 1 to 20; AnaSpec) emulsified in $0.2 \mathrm{~mL}$ CFA. The immunization was performed via s.c. injection both flanks ( $50 \mu \mathrm{L}$ each side) as well as the base of the tail $(100 \mu \mathrm{L})$. Both murine strains also received an i.p. injection of $0.2 \mu \mathrm{g}$ Bordetella pertussis toxin (Sigma) concurrent with immunization. Mice receiving CFA and Bordetella pertussis toxin without the peptide served as a nondisease control. In addition, conventional EAU was induced in B10.RIII mice with immunization of $300 \mu \mathrm{g}$ human IRBP peptide (residues 161 to 180) emulsified in 0.2
$\mathrm{mL}$ CFA along with injection of $0.2 \mu \mathrm{g}$ Bordetella pertussis toxin, ${ }^{10}$ and in C57BL/6 mice with immunization of $500 \mu \mathrm{g}$ human IRBP peptide (residues 1 to 20) emulsified in $0.2 \mathrm{~mL}$ CFA along with injection of $0.4 \mu \mathrm{g}$ Bordetella pertussis toxin $^{18}$ to serve as disease controls.

\section{Digital Fundus Imaging and Scoring}

A Micron III (Phoenix, Pleasanton, CA) retinal imaging system was used for taking fundus images weekly after immunization. Mice were anesthetized using ketamine-xylazine $(100 \mathrm{mg} / \mathrm{kg}+20 \mathrm{mg} / \mathrm{kg}$, respectively), and pupils were dilated using $0.5 \%$ tropicamide. Eyes were kept moist by application of ocular lubricant (Genteal; Alcon, Fort Worth, TX), and were examined for optic disc inflammation, retinal infiltrates and scars, and retinal vessel changes. Fundus images were taken and scored on a scale of 0 to 4 using a valid and reproducible grading system, as previously described. ${ }^{16}$

\section{Retinal Imaging by Spectral Domain OCT}

After anesthesia and pupil dilation, as detailed above, mice were restrained in a mounting tube fixed on a sixaxis platform. Ocular lubricant (Genteal gel) was applied to both eyes to prevent drying of the cornea. A spectral domain optical coherence tomography (OCT) system (Bioptigen version 1.4.0; Durham, NC) was used for in vivo noncontact imaging of eyes. B scan was obtained with images centered on the optic nerve head. Retinal thickness was defined as distance from the interface of the vitreous and the ganglion cell layer to the interface of the retinal pigment epithelium and choroid, and measured manually from each averaged B-scan OCT image, approximately $350 \mu \mathrm{m}$ away from the edge of the optic disc, as described previously. ${ }^{15,19}$

\section{Electroretinography}

Following overnight dark adaptation, mice were prepared for electroretinography under dim red light. After anesthesia and pupil dilation, as detailed above, one drop of $0.9 \%$ sterile saline was applied on the cornea to prevent dehydration and to allow electrical contact with the recording electrode (gold wire loop). A 25-gauge platinum needle, inserted subcutaneously in the forehead, served as reference electrode, whereas a needle inserted subcutaneously near the tail served as the ground electrode. A series of flash intensities were produced by an Espion Ganzfeld (Diagnosys, Lowell, MA) to test both scotopic (darkadapted) and photopic (light-adapted) responses. The major electroretinography components (a-wave and b-wave) were measured using the Espion software version 6 (Diagnosys). ${ }^{15,17}$ The a-wave amplitude was measured from the baseline to the trough of the a-wave, and b-wave amplitude was measured from the trough of the a-wave to the peak of the b-wave. 

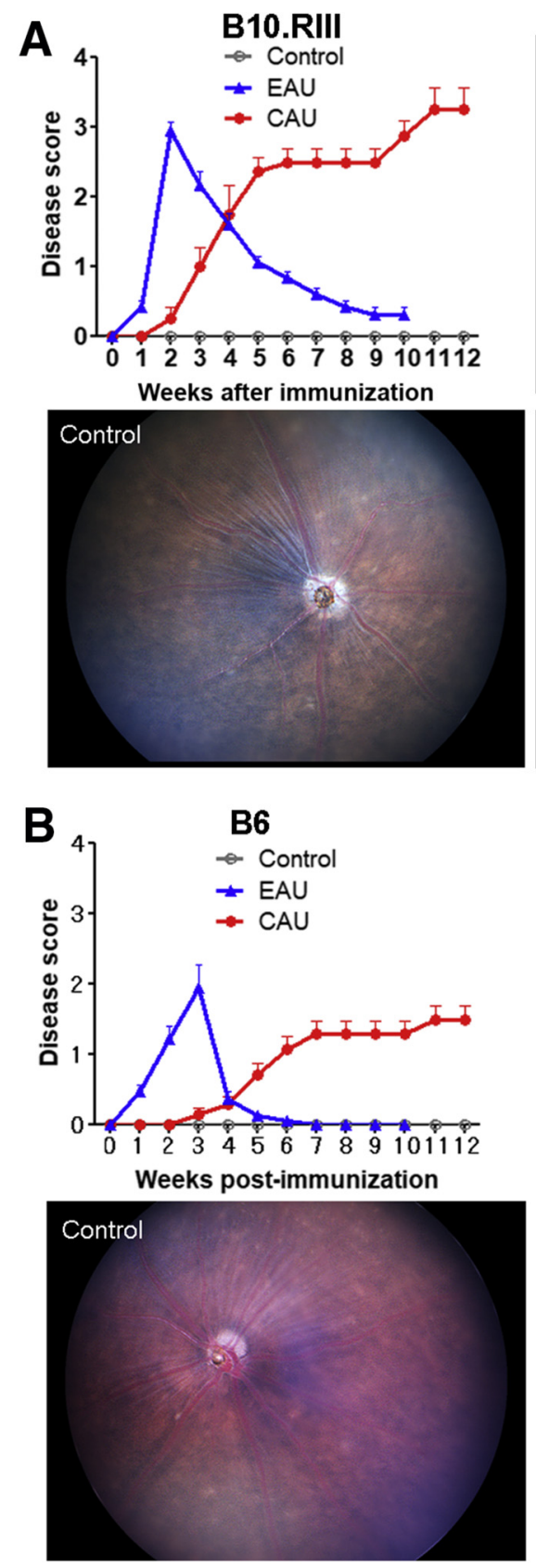
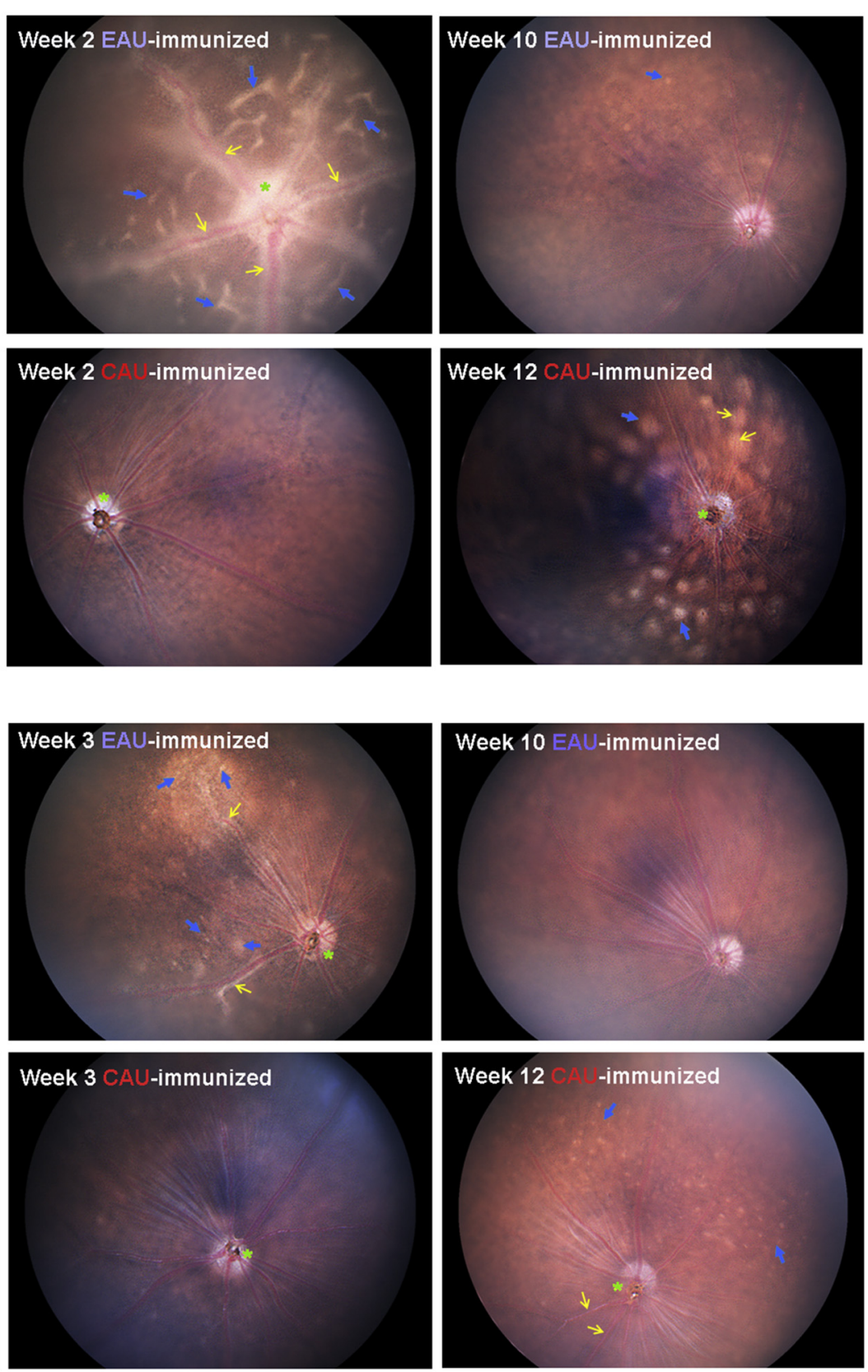

Figure 1 Fundoscopic evaluation of chronic uveitis disease activity. A: Following immunization in B10.RIII mice, digital fundus images were taken on a weekly basis, and graded on a scale of 0 to 4 by averaging the scores of optic disc, retinal vessel, and retinal tissue changes. Representative digital fundus images at indicated time points are shown. At week 2, EAU reaches disease peak, showing severe optic disc inflammation with some vessels in the optic disc masked (asterisk, scoring of 4/4), severe perivascular cuffing (yellow arrows, scoring of 4/4), and multiple retinal linear lesions (blue arrows, scoring of 4/ 4), which is finally graded as 4. In contrast, CAU at week 2 only shows slightly blurred optic disc margins (asterisk, scoring of 1/4) without vessel or retinal tissue changes (scoring of $0 / 4$ for each), which is finally graded as 0.3 . By week 10 , EAU shows almost complete disease resolution with only isolated small retinal lesions identified (blue arrow, scoring of $1 / 4$ ), which is finally graded as 0.3 . However, CAU shows disease progression and reaches disease peak by week 12, exhibiting extensive inflammation in the optic disc and juxtapapillary area with some vessels in the optic disc masked and invisible (asterisk, scoring of 3/4), sclerotic vessels with moderate perivascular cuffing (yellow arrows, scoring of 3/4), and pan-retinal atrophy with many large lesions (blue arrows, scoring of 4/4), which is finally graded as 3.3. B: Following immunization in C57BL/6 (B6) mice, digital fundus images were similarly taken and scored. Representative digital fundus images at indicated time points are shown. At week 3, EAU reaches disease peak, showing swelling of optic disc and blurred optic disc margins (asterisk, scoring of 2/4), extensive perivascular cuffing (yellow arrows, scoring of 3/4), and diffuse and linear whitish lesions (blue arrows, scoring of 4/4), which is finally graded as 3 . In contrast, CAU shows slightly blurred optic disc margins (asterisk, scoring of 1/4) with normally appearing retinal vessels and tissues (scoring of $0 / 4$ for each), which is finally graded as 0.3 on average. By week 10, EAU shows complete disease resolution; yet, CAU shows disease progression and reaches disease peak by week 12 with slightly blurred optic disc margins (asterisk, scoring of 1/4), engorged vessels (yellow arrows, scoring of 1/4), and pan-retinal atrophy with numerous small lesions (blue arrows, scoring of 3/4), which is finally graded as 1.7. Data are presented as means \pm SEM of a single representative experiment (out of two performed) of 14 eyes from seven mice in CAU group, and 10 eyes from five mice in each of EAU and control (mice receiving CFA and Bordetella pertussis toxin without the peptide) group (A and B). B6, C57BL/6. 

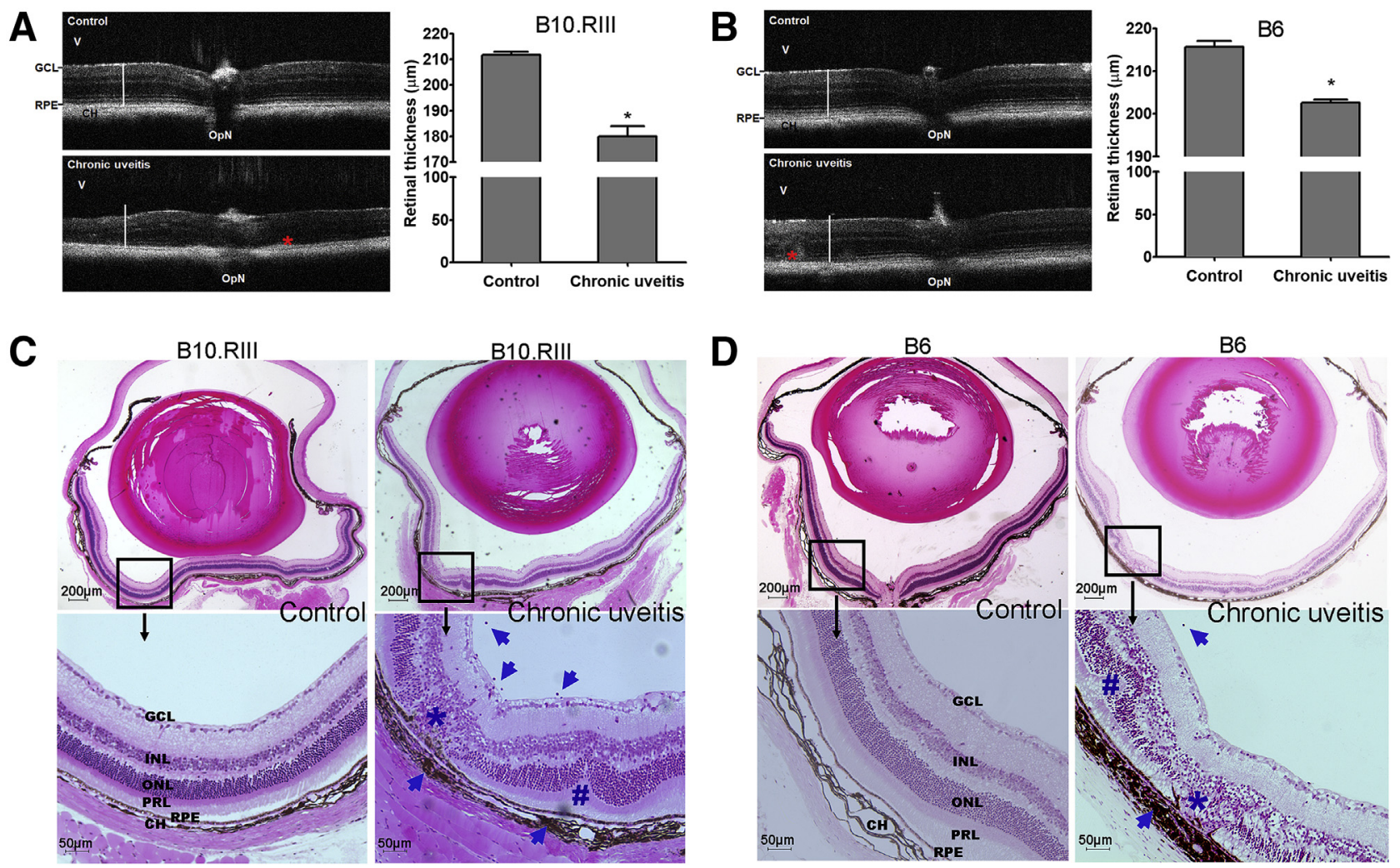

Figure 2 Optical coherence tomography (OCT) assessment and histopathology of retina in chronic uveitis. A and B: Retinal anatomy of B10.RIII (A) and $\mathrm{C57BL} / 6$ (B6; B) mice was evaluated by OCT in control (mice receiving CFA and Bordetella pertussis toxin without the peptide) and chronic uveitis mice at week 12. Representative images (left panels) and summary bar charts (right panels) are shown. Retinal thickness was measured from the interface of the vitreous $(\mathrm{V})$ and the ganglion cell layer $(\mathrm{GCL})$ to the interface between the retinal pigment epithelium (RPE) and choroid (CH). White bars in the images represent the normal retinal thickness in each mouse strain, which indicates the reduced thickness in mice with chronic uveitis. Asterisks indicate focal areas of thickening in both strains of chronic uveitis. $\mathbf{C}$ and $\mathbf{D}$ : Representative sections of hematoxylin and eosin-stained eyeballs at week 12 are shown. Characteristic changes in chronic uveitis in B10.RIII (C) and B6 (D) mice include the following: i) degeneration of the retinal pigment epithelium, the photoreceptor layer, and nuclear layers (asterisk); ii) retinal folds (hash mark); and iii) inflammatory infiltrates in the vitreous and choroid (arrows). Data are given as means \pm SEM (A and $\mathbf{B}) ; n=5$ (A and $\mathbf{B})$. ${ }^{*} P<0.05$ versus control. Scale bars: $200 \mu \mathrm{m}(\mathbf{C}$ and $\mathbf{D}$, top rows); $50 \mu \mathrm{m}$ (C and $\mathbf{D}$, bottom rows). INL, inner nuclear layer; $0 \mathrm{NL}$, outer nuclear layer; $0 \mathrm{pN}$, optic nerve; PRL, photoreceptor layer.

\section{Histology}

The whole eyeball was excised and fixed in $10 \%$ formalin. After dehydration, the specimens were embedded in methacrylate, cross-sectioned, and stained with hematoxylin and eosin. The morphology of the retina and choroid was observed under a microscope (Eclipse E800; Nikon, Tokyo, Japan) with a $10 \times$ objective. $^{20}$

\section{Flow Cytometry Analysis and Reagents}

At week 12, retinal tissues, lymph nodes, spleens, blood (from retrobulbar sinus), and bone marrow (from femur and tibia bones) were collected, and single-cell suspensions were prepared using a $70-\mu \mathrm{m}$ cell strainer (BD Biosciences, Franklin Lakes, NJ). Red blood cells were lysed in appropriate samples using lysis buffer (Sigma-Aldrich, St. Louis, MO) before cell staining. The following antibodies were used for flow cytometry analysis: Brilliant Violet 421-conjugated anti-CD4, fluorescein isothiocyanate-conjugated anti-interferon (IFN)- $\gamma$,
PerCP/Cy5.5-conjugated anti-CD44, phosphatidylethanolamine-conjugated anti-IL-7R, Alexa Fluor 700-conjugated anti-IL-15R (BioLegend, San Diego, CA), and allophycocyanin- or phosphatidylethanolamine-Cy7-conjugated antiIL-17A (ThermoFisher Scientific, Waltham, MA). For intracellular IL-17A and IFN- $\gamma$ staining, cells were stimulated with $50 \mathrm{ng} / \mathrm{mL}$ phorbol 12-myristate 13 -acetate and $500 \mathrm{ng} / \mathrm{mL}$ ionomycin (Sigma-Aldrich) for 6 hours at $37^{\circ} \mathrm{C}$ and $5 \% \mathrm{CO}_{2}$ in the presence of GolgiStop $(4 \mu \mathrm{L}$ per $6 \mathrm{~mL}$ cell culture; BD Biosciences) to inhibit cytokine secretion. Stained cells were examined with an LSR II flow cytometer (BD Biosciences), and the results were analyzed using FlowJo software version 10 (Tree Star, Ashland, OR).

\section{Statistical Analysis}

Unpaired two-tailed $t$-tests were used. All statistical analyses were performed with Prism software version 5 (GraphPad Software, San Diego, CA), and differences were considered significant at $P<0.05$. 

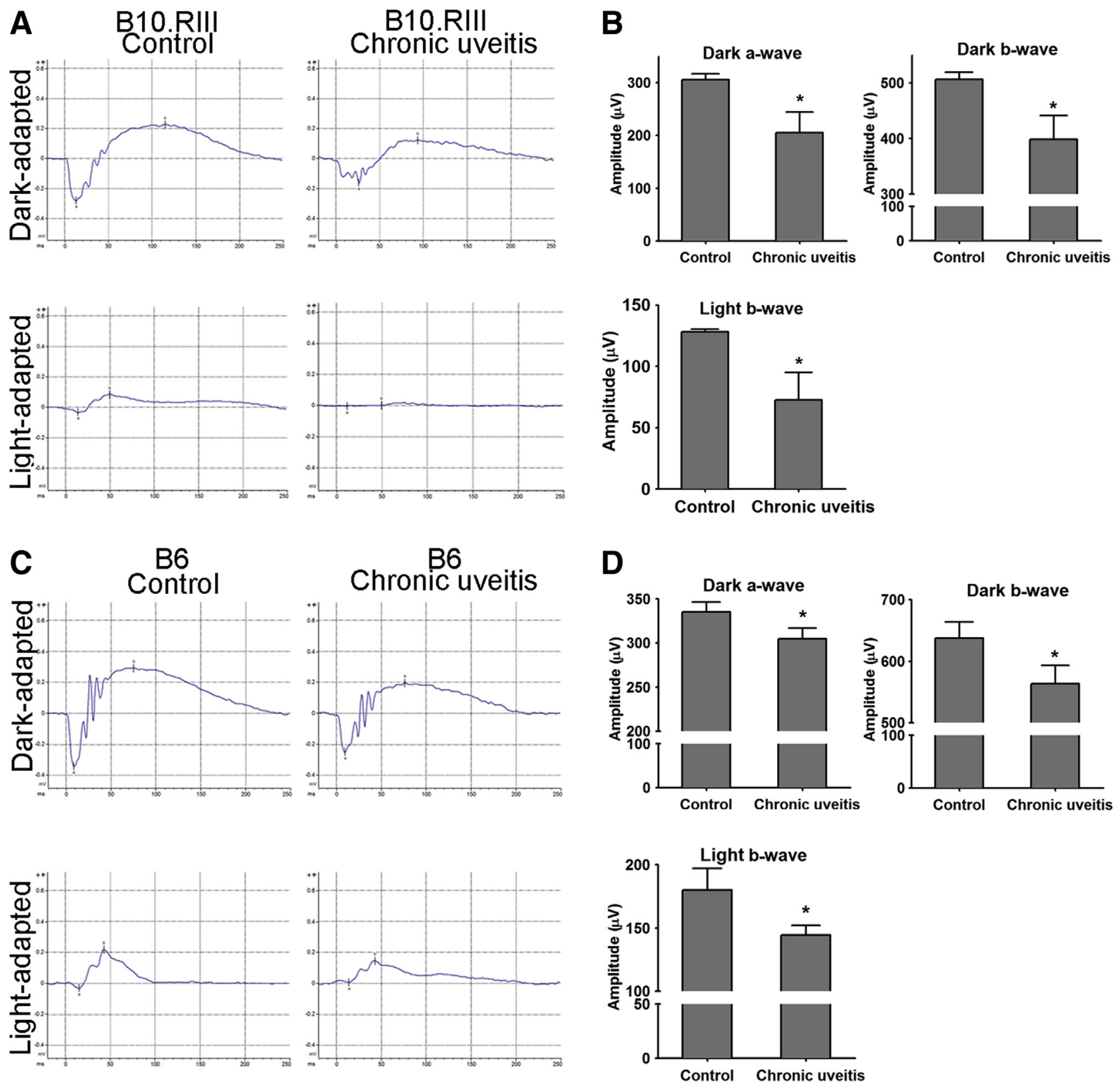

Figure 3 Electroretinography (ERG) evaluation of retinal function in chronic uveitis. ERG responses from dark- and light-adapted eyes were recorded and analyzed at week 12. Representative ERG responses to light stimuli at 24.1 and $25.6 \mathrm{~cd} \mathrm{~s} / \mathrm{m}^{2}$ for scotopic dark- and photopic light-adapted ERG in B10.RIII (A) and $\mathrm{C} 57 \mathrm{BL} / 6(\mathrm{~B} 6 ; \mathrm{C})$ mice are shown, respectively. The a-wave amplitude was measured from the baseline to the trough of the a-wave, and $\mathrm{b}$-wave amplitude was measured from the trough of the a-wave to the peak of the b-wave. Amplitudes are depicted in bar charts for B10.RIII (B) and B6 (D) mice. Data shown are means \pm SEM (B and $\mathbf{D}) . n=5$ animals in each group (B and $\mathbf{D}) .{ }^{*} P<0.05$ versus control.

\section{Results}

Murine Chronic Autoimmune Uveitis Is Characterized by Progressive Clinical Disease, in Contrast to the Acute, Self-Limiting EAU Course

Conventional EAU was induced in B10.RIII mice with immunization of $300 \mu \mathrm{g}$ human IRBP peptide (residues 161 to 180$),{ }^{10}$ and in C57BL/6 mice with immunization of 500 $\mu \mathrm{g}$ human IRBP peptide (residues 1 to 20 ). ${ }^{18}$ To induce CAU, B10.RIII mice were immunized with $50 \mu \mathrm{g}$ human IRBP peptide (residues 161 to 180), and C57BL/6 mice were immunized with $150 \mu \mathrm{g}$ human IRBP peptide (residues 161 to 180 ) and $300 \mu \mathrm{g}$ human IRBP peptide (residues 1 to 20). Following immunization, the development of uveitis was evaluated by fundus examination on a weekly basis. Clinical disease severity was graded according to three parameters-optic disc, retinal vessels, and retinal 


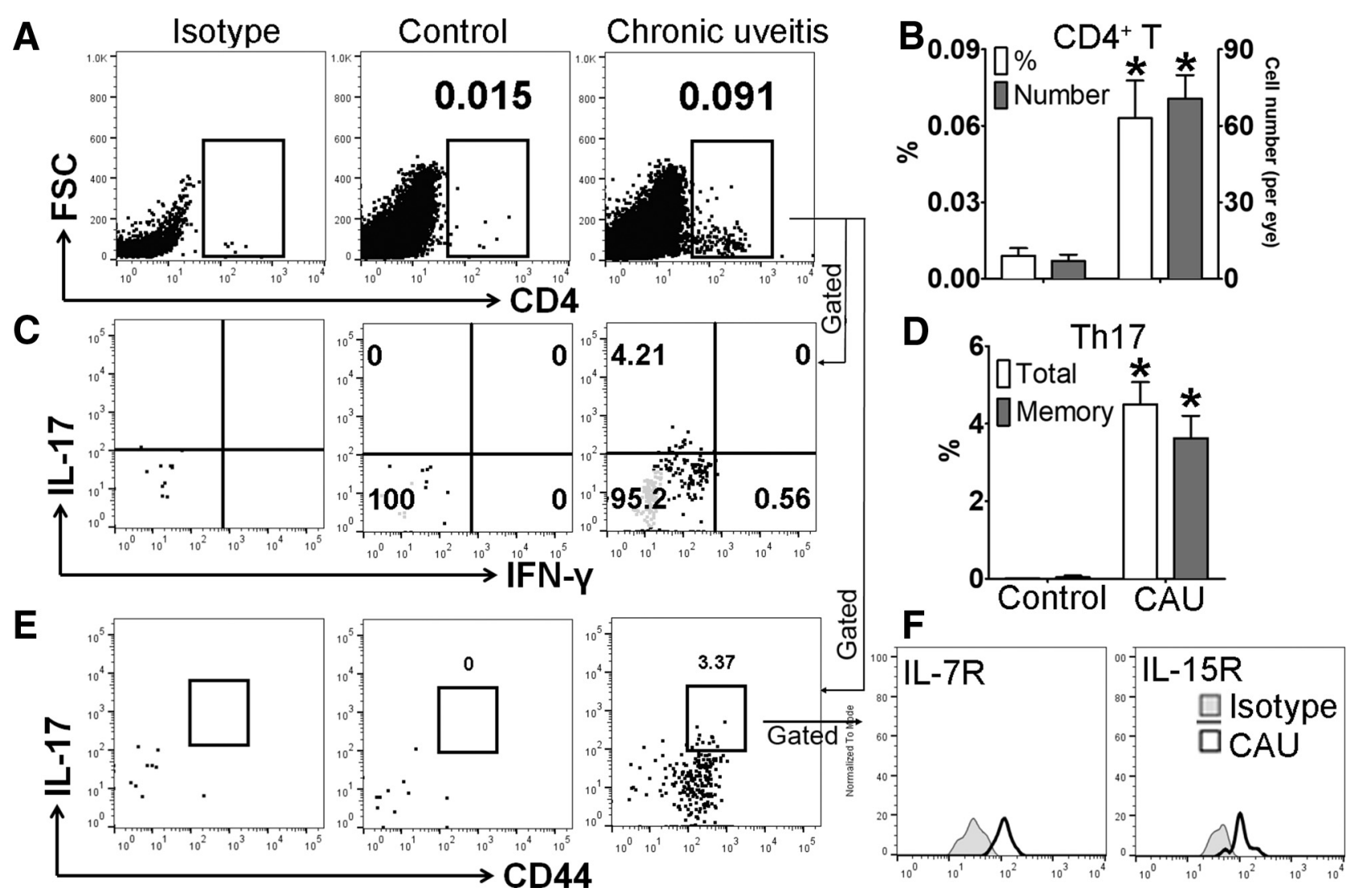

Figure 4 Memory T-helper 17 (Th17) response in retinal tissues in B10.RIII mice with chronic autoimmune uveitis (CAU). Retinal tissues were harvested and prepared for flow cytometric assessment at week 12. Frequencies and numbers of total $\mathrm{CD}_{4}{ }^{+} \mathrm{T}$ cells in retina were determined after debris and doublet exclusions (A), and are summarized in bar chart (B). Furthermore, frequencies of IL17 ${ }^{+}$IFN- $\gamma^{-}$CD4 ${ }^{+}$(total Th17) and CD $44^{\mathrm{hi}} \mathrm{IL}-17^{+} \mathrm{CD} 4^{+}$(memory Th17) cells among total CD4 ${ }^{+} \mathrm{T}$ cells were examined with representative flow cytometry dot plots (C and $\mathbf{E}$ ), and bar charts summarizing total and memory Th17 cells (D). CD44 ${ }^{\mathrm{hi}}$ Th17 cells were further characterized according to the expression of the memory markers IL-7R and IL-15R (F). Results are from a single experiment (with each sample pooled from four eyes) and are representative of two performed. $n=3$ per group. ${ }^{*} P<0.05$ versus control. FSC, forward scatter; IFN- $\gamma$, interferon- $\gamma$.

tissue changes-each of which was scored from 0 to 4 , with the final score calculated by dividing the total score by 3 , as previously described. ${ }^{16}$ Consistent with the previous reports, ${ }^{12-15}$ the EAU-immunized B10.RIII and C57BL/6 mice reached peak disease by day 14 and 21 , respectively (with average scores of 2.9 and 2.0 , respectively), and demonstrated a spontaneous rapid decline in disease severity following disease peak (Figure 1). In contrast, the CAUimmunized B10.RIII and C57BL/6 mice did not start to show any uveitis changes until day 14 and 21 , respectively (with average scores of 0.3 and 0.1 , respectively), and disease severity did not decrease over the 12-week observation period. The progression of disease was significantly slower in our CAU model than in the EAU model, and overt uveitis (average scores $>2.0$ in B10.RIII and $>0.7$ in C57BL/6) was not observed until weeks 5 to 7 (Figure 1). Critically, and in contrast to EAU, spontaneous resolution of disease was not observed in either our immunized B10.RIII or C57BL/6 mice. The B10.RIII mice in this study exhibited progressive increases in disease severity until week 10 , at which point disease stabilized until the end of observation at week 12 , demonstrating severe inflammation in the optic disc and pan-retinal atrophy with sclerotic vessels (Figure 1A). In C57BL/6 mice, gradual increases in disease severity were observed until week 7 , at which point a plateau was reached that persisted until the end of observation at week 12 , demonstrating blurred optic disc margins and multiple retinal small lesions with engorged vessels (Figure 1B).

\section{Chronic Autoimmune Uveitis Is Characterized by Retinal Degeneration and Destruction}

OCT has been used to evaluate retinal pathology in mouse models of uveitis by measuring retinal thickness. ${ }^{15,19}$ EAU is characterized by increased retinal thickness during the acute inflammatory response. ${ }^{15}$ In contrast, in our CAU models, retinal thickness measured at week 12 by OCT was significantly reduced in both strains (Figure 2, A and B). This observation is consistent with degeneration of retinal tissues in chronic uveitis. Notably, in line with the higher disease scores observed in B10.RIII CAU mice (Figure 1), 


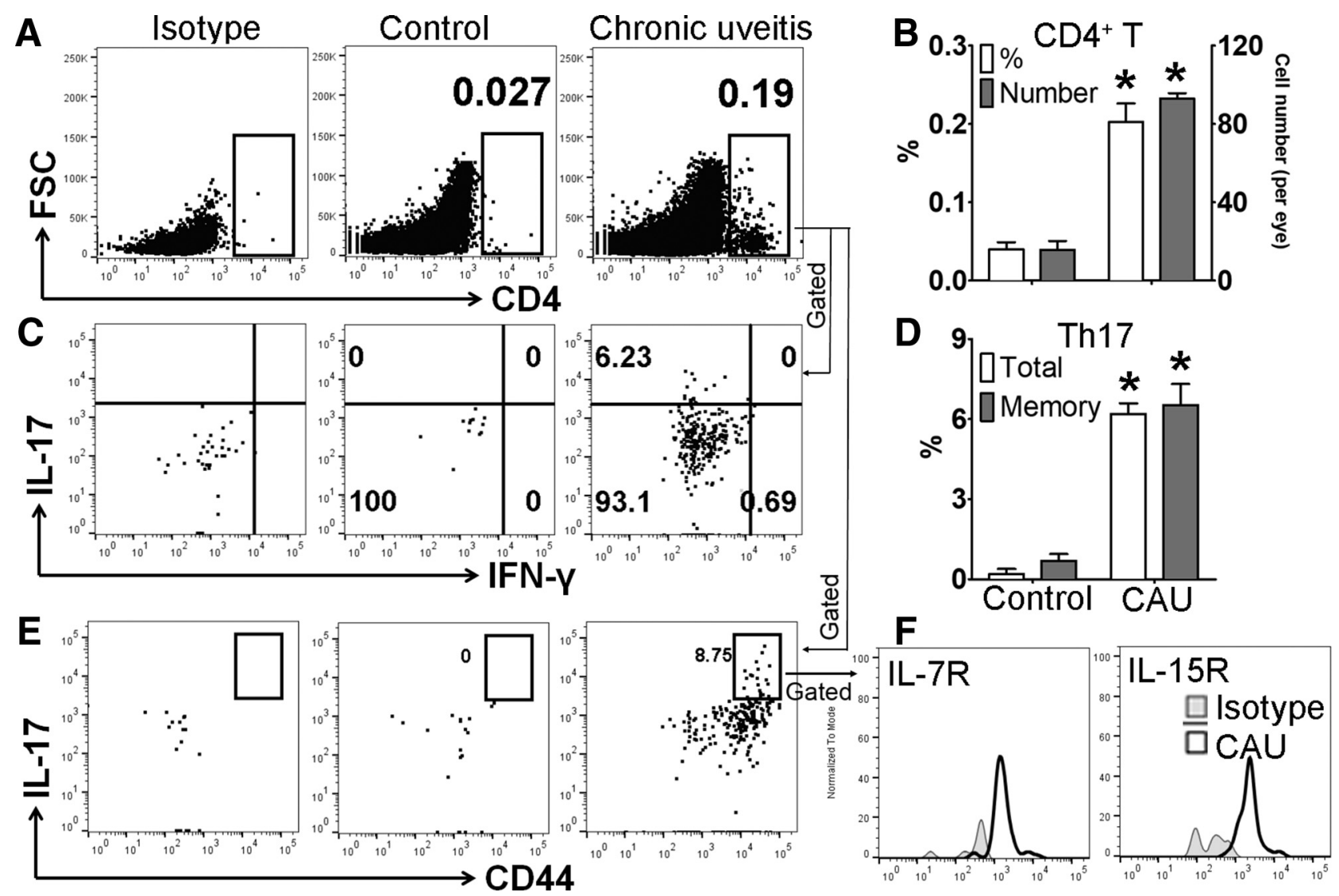

Figure 5 Memory T-helper 17 (Th17) response in retinal tissues in C57BL/6 mice with chronic autoimmune uveitis (CAU). Retinal tissues were harvested and prepared for flow cytometric assessment at week 12. Frequencies and numbers of total $\mathrm{CD}^{+}{ }^{+} \mathrm{T}$ cells in retina were determined after debris and doublet exclusions (A), and are summarized in bar chart (B). Furthermore, frequencies of IL17 ${ }^{+}$IFN- $\gamma^{-} \mathrm{CD}^{+}$(total Th17) and CD44 ${ }^{\mathrm{hi}} \mathrm{IL}-17^{+} \mathrm{CD}^{+}$(memory Th17) cells among total $C D 4^{+} T$ cells were examined with representative flow cytometry dot plots (C and $\left.\mathbf{E}\right)$, and bar charts summarizing total and memory Th17 cells (D). CD44 ${ }^{\text {hi }}$ Th17 cells were further characterized according to the expression of the memory markers IL-7R and IL-15R (F). Results are from a single experiment (with each sample pooled from four eyes) and are representative of two performed. $n=3$ per group. ${ }^{\star} P<0.05$ versus control. FSC, forward scatter; IFN- $\gamma$, interferon- $\gamma$.

the reduction of retinal thickness is more prominent in B10.RIII mice compared with C57BL/6 CAU mice, and is accompanied by more severe disruption of retinal lamination in the B10.RIII mice, such that it is harder to identify individual layers than in C57BL/6 CAU mice (Figure 2, A and B). In both strains, hyperreflective thickening was present at the level of the retinal pigment epithelia. To further determine the pathologic changes, whole eyeballs were harvested at the end of clinical observation (ie, week 12) and subjected to histologic examination. In contrast to the marked infiltration of inflammatory cells observed in the retina and vitreous in EAU, ${ }^{15,17}$ both B10.RIII and C57BL/6 CAU mice showed few vitreous or retinal infiltrates, but exhibited prominent choroiditis with damage of the adjacent retinal pigment epithelium - the outer blood-retina barrier (Figure 2, C and D). Consistent with the OCT findings, extensive destruction of the photoreceptor and outer nuclear layers was observed (Figure 2, C and D). Histologic examination demonstrated characteristic retinal folds in CAU (Figure 2, C and D).

\section{Chronic Autoimmune Uveitis Is Characterized by Impaired Retinal Function}

Retinal function in CAU was evaluated using electroretinography. Both dark-adapted responses (evaluating scotopic vision mediated by rod cells) and light-adapted responses (assessing photopic vision mediated by cone cells) on full-field electroretinography were recorded at week 12. Consistent with the retinal degeneration detected by OCT, both B10.RIII and C57BL/6 CAU mice demonstrated significantly decreased amplitudes of darkadapted a-waves, dark-adapted b-waves, and light-adapted b waves, compared with their respective controls (Figure 3). Furthermore, the reduction of amplitudes was greater in B10.RIII than in C57BL/6 CAU mice, with an average $33 \%$ versus $10 \%$ drop in dark-adapted a-waves, a $21 \%$ versus $12 \%$ drop in dark-adapted b-waves, and a $43 \%$ versus $20 \%$ drop in light-adapted b-waves, respectively (Figure 3). Normal control C57BL/6 mice exhibited larger baseline response amplitudes than the B10.RIII strain, a 
A
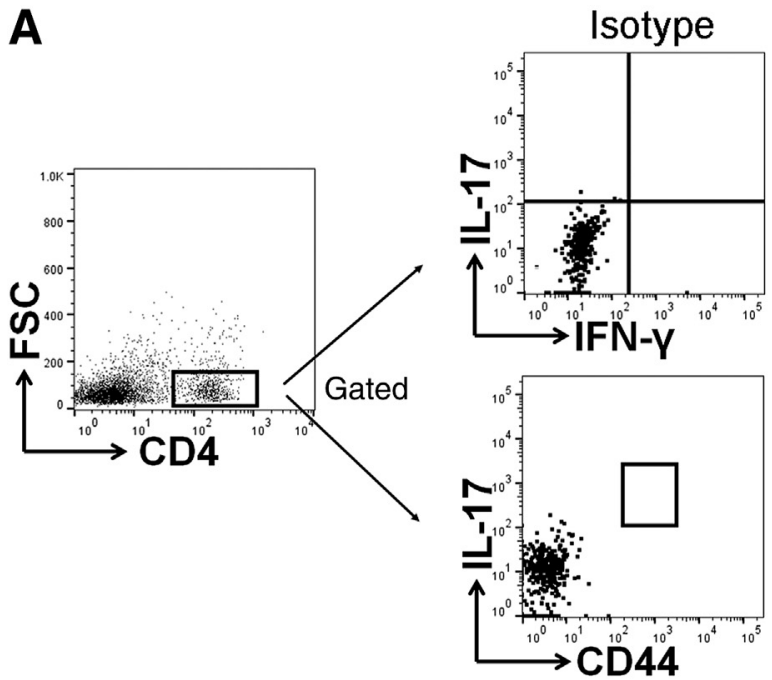

B IL-7R on CD44 ${ }^{\text {nillL-}}-17^{+} C D 4^{+}$

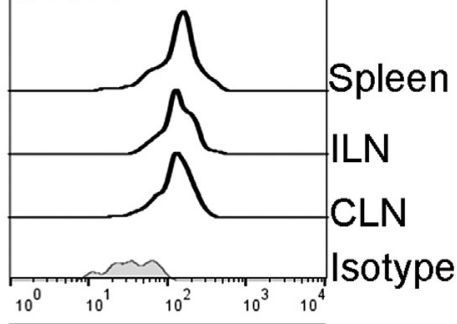

IL-15R on CD44 $4^{\mathrm{h}}$ IL-17+CD4 ${ }^{+}$

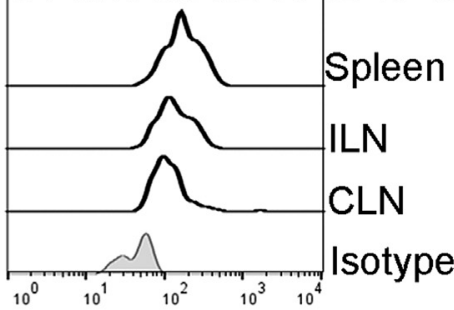

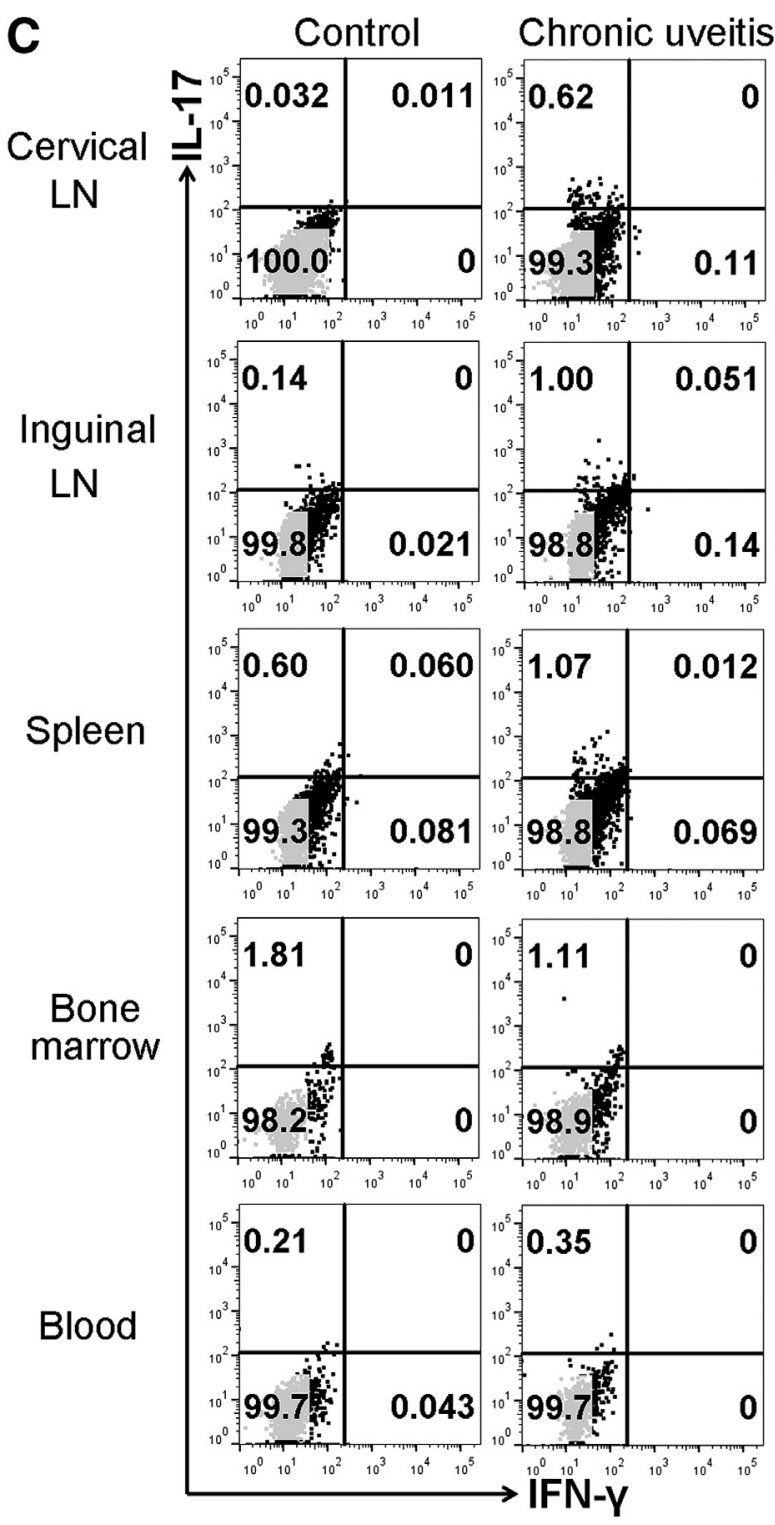
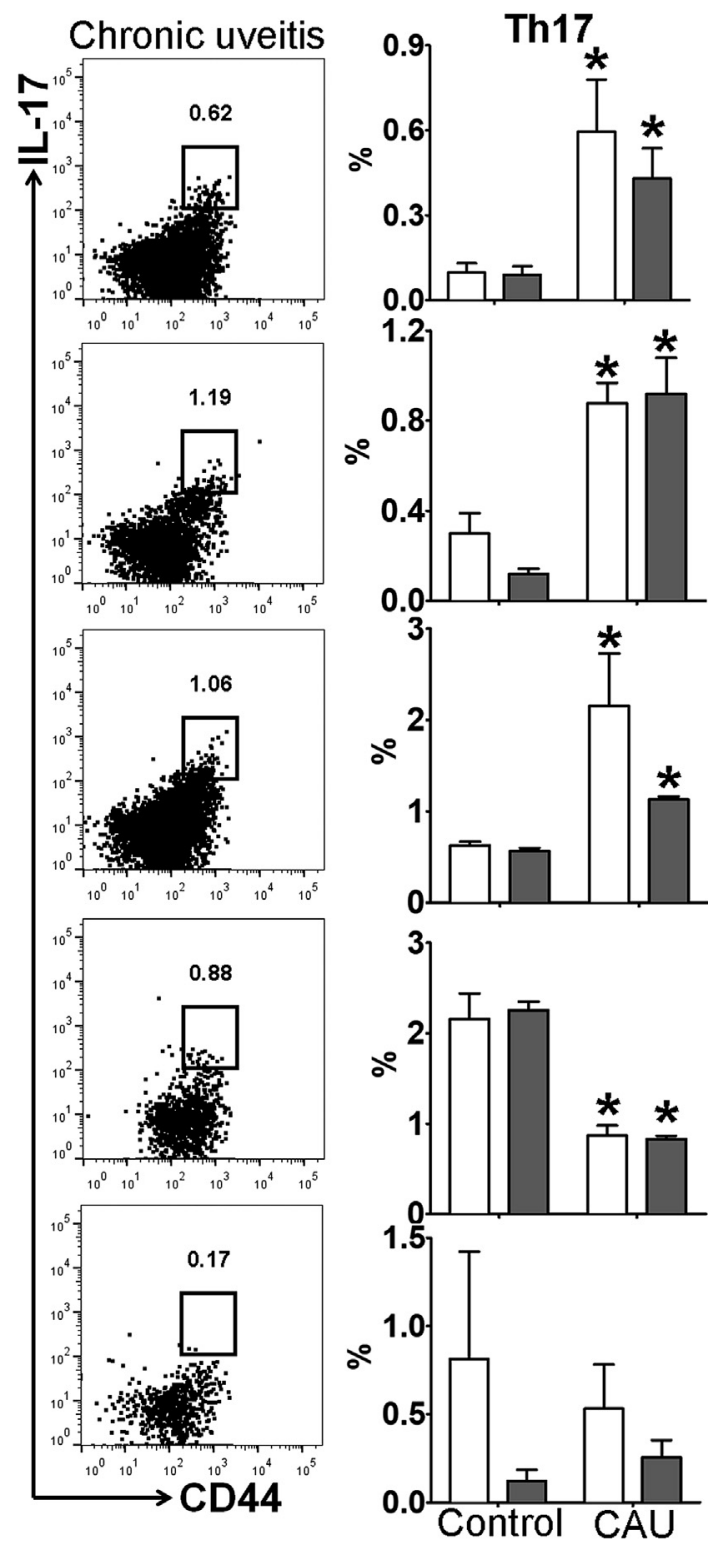
direct comparison that has not (to our knowledge) previously been made.

\section{Chronic Autoimmune Uveitis Is Primarily Characterized by a Memory Th17 Cell Population, Distinct from Effector Th17 Cells Identified in Acute Uveitis}

Previous studies have shown that acute uveitis in EAU can be either Th17 or Th1 driven. ${ }^{8,9,21}$ Accordingly, we evaluated whether similar T-cell immunity is involved in CAU. Local T-cell infiltration was first examined at week 12 , and in contrast to control mice, which showed few $\mathrm{CD}^{+} \mathrm{T}$ cells in retina, mice with $\mathrm{CAU}$ exhibited significant infiltration of $\mathrm{CD}^{+} \mathrm{T}$ cells, of which the predominant population was IL- $17^{+}$IFN- $\gamma^{-}$Th17 cells (Figures 4 and 5), rather than $\mathrm{IL}-17^{-} \mathrm{IFN}-\gamma^{+}$Th1 or $\mathrm{IL}-17^{+} \mathrm{IFN}-\gamma^{+}$ Th17/Th1 cells (Supplemental Figure S1). In autoimmune inflammatory conditions, pathogenic $\mathrm{T}$ cells may also reside in peripheral lymphoid organs. ${ }^{22-24}$ Accordingly, the T-cell response was examined in lymph nodes [cervical (draining ocular tissues) and inguinal (draining initially injected antigen)], spleen, bone marrow, and peripheral blood. Consistently higher numbers of Th17 cells were found in the eye-draining cervical lymph nodes, distal inguinal lymph nodes, and spleens in both B10.RIII and C57BL/6 mice with CAU relative to control mice. However, no significant difference in Th17 cell numbers was observed in the bone marrow or peripheral blood in CAU (Figures 6 and 7).

Next, it was explored whether the Th17 cells identified in the chronic stage of disease were the same as those reported in acute uveitis. It is known that immunologic memory is a defining feature of adaptive immunity, and antigen-experienced memory $\mathrm{T}$ cells that survive the acute phase exert a stronger and accelerated recall response following repeat exposures to the same antigen. ${ }^{25}$ Although conferring long-term protection during infection and after vaccination, immunologic memory can play a pathogenic role in chronic autoimmune disorders. $^{23,24,26,27}$ We thus hypothesized that a portion of the effector Th17 cells mediating acute uveitis ${ }^{9,28}$ develop into long-lived memory Th17 cells in chronic uveitis. Accordingly, the Th17 cells identified in CAU retina and lymphoid tissues were further characterized, and it was found that they consistently exhibit memory Th17 phenotypes, with high levels of CD44, IL-7R, and IL-15R expression (Figures 4, 5, 6, 7). ${ }^{23,29-31}$

\section{Discussion}

Our understanding of the immunopathogenic mechanisms that initiate and perpetuate inflammation in chronic autoimmune uveitis is incomplete. The goal of this study was to establish a wild-type murine model that recapitulates key histologic and functional characteristics of human chronic autoimmune uveitis. By modifying antigen dose and peptide fragments from conventional EAU models (in which spontaneous disease resolution is observed), models of CAU were successfully established in B10.RIII and C57BL/6 wild-type mice. Specifically, in these animals, chronic chorioretinitis was observed with damage to the outer blood-retina barrier, retinal degeneration, photoreceptor destruction, and impaired retinal function. Furthermore, by evaluating single-cell suspensions derived from retinal tissues and peripheral lymphoid organs using flow cytometry, it was shown that memory Th17 cells characterize the immune response in CAU.

Conventional EAU models employ pathogenic epitopes of IRBP peptides to induce disease in various animal species and strains, ${ }^{32}$ in which severe, acute intraocular inflammation is followed by spontaneous resolution..$^{10,28,33,34}$ These models involve the immunization of B10.RIII mice with 100 to $300 \mu \mathrm{g}$ of human IRBP peptide (residues 161 to $180)^{10,33}$ or the immunization of Lewis rats with 30 to 100 $\mu \mathrm{g}$ of bovine IRBP peptide (residues 1177 to 1191 ). ${ }^{28,34}$ C57BL/6 mice are less susceptible to the induction of uveitis, ${ }^{34}$ and higher doses of immunizing antigen are required for disease induction in this strain $(500 \mu \mathrm{g}$ to $5 \mathrm{mg}$ human IRBP peptide residues 1 to 20). ${ }^{18,35}$ Since mice are immunologically well characterized, and given the relative abundance of investigative tools available for murine studies, we aimed to develop models of CAU in B10.RIII and C57BL/6 mice. CAU was successfully induced by using lower doses of antigen than those employed in EAU models. Specifically, B10.RIII mice were immunized with $50 \mu \mathrm{g}$ human IRBP peptide (residues 161 to 180), and C57BL/6 mice with $150 \mu \mathrm{g}$ human IRBP peptide (residues 161 to 180 ) plus $300 \mu \mathrm{g}$ human IRBP peptide (residues 1 to 20). Notably, B10.RIII mice exhibited more severe clinical disease compared with C57BL/6 mice, which correlates with the difference in susceptibility of these murine strains to uveitis induction, and is consistent with differences in acute disease severity in EAU models (Figure 1).

Chronic murine uveitis has previously been observed. ${ }^{15,36}$ Notably, Chen et $\mathrm{al}^{15}$ have reported that a portion (approximately 25\%) of B10.RIII mice induced with the

\footnotetext{
Figure 6 Memory T-helper 17 (Th17) response in lymphoid tissues in B10.RIII mice with chronic autoimmune uveitis. Cervical draining lymph node (CLN), distal inguinal LN (ILN), spleen, bone marrow, and peripheral blood samples were collected and prepared for flow cytometric assessment at week 12. A: Gating strategy and isotype controls for analyzing total and memory Th17 cells. B: Representative flow cytometry histograms show the expression of IL-7R and IL-15R on CD44 ${ }^{\text {hi }}$ Th17 cells. Results are from a single experiment and are representative of two performed. C: Frequencies of IL17 ${ }^{+}$IFN-

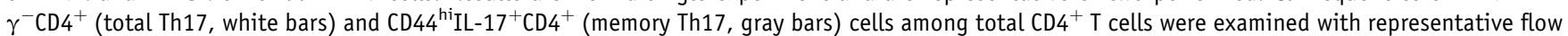
cytometry dot plots shown on the left, and bar charts summarizing total and memory Th17 cells shown on the far right. $n=3$ to 4 per group (B). ${ }^{*} P<0.05$ versus control. FSC, forward scatter; IFN- $\gamma$, interferon- $\gamma$.
} 
A
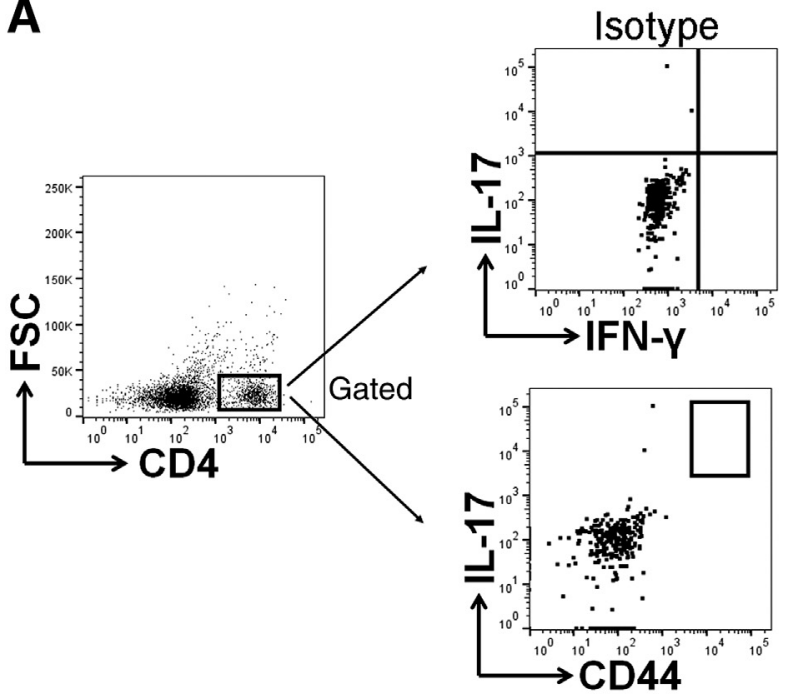

B IL-7R on CD44 hill- $17^{+}$CD4 ${ }^{+}$

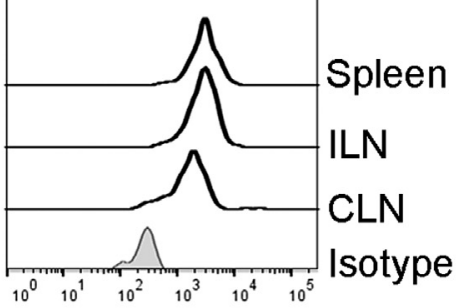

IL-15R on CD44 4 iL-17+CD4+

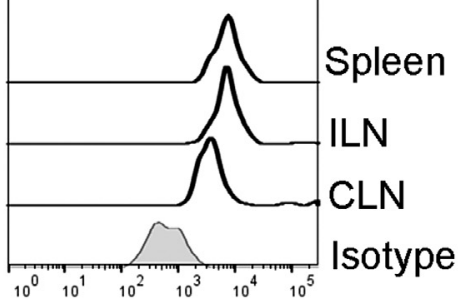

C

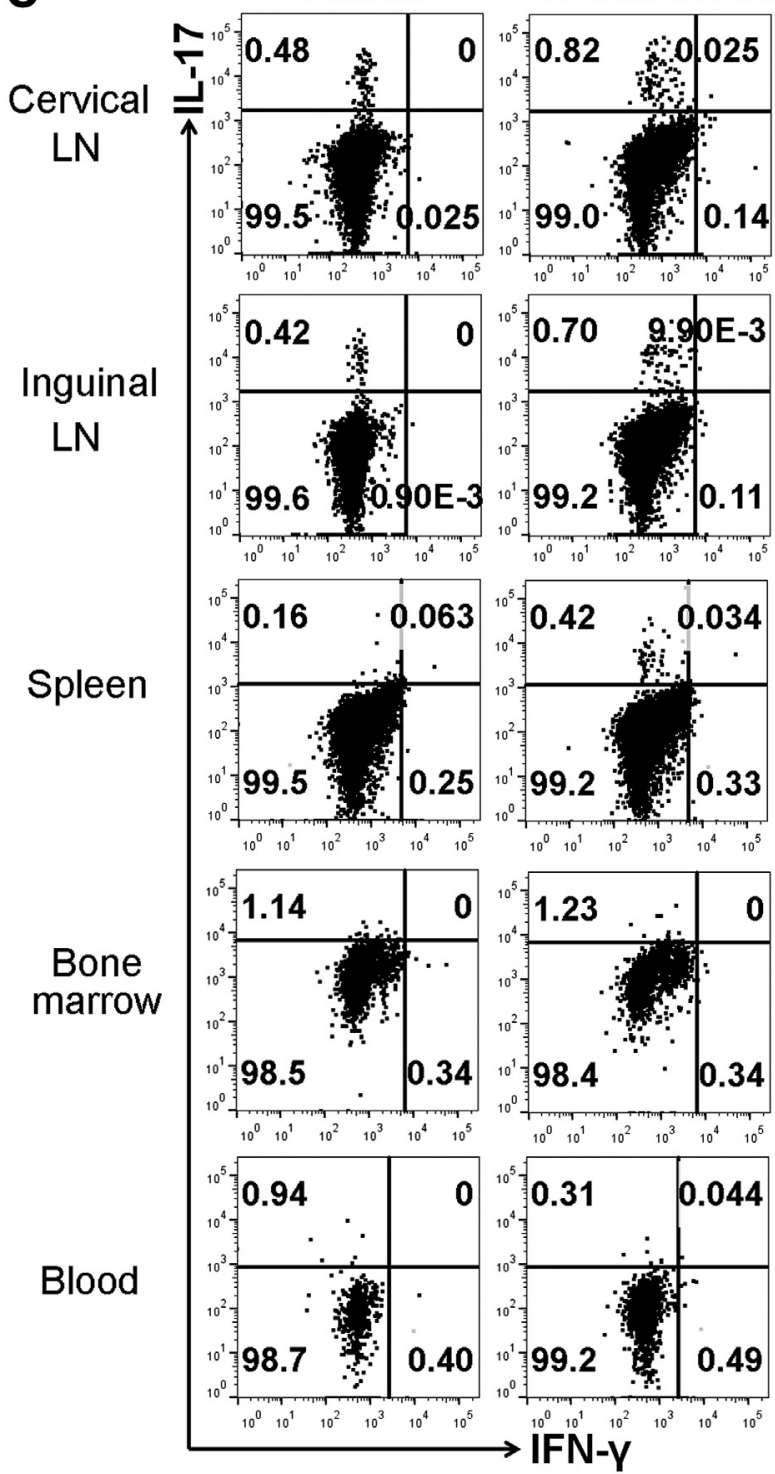

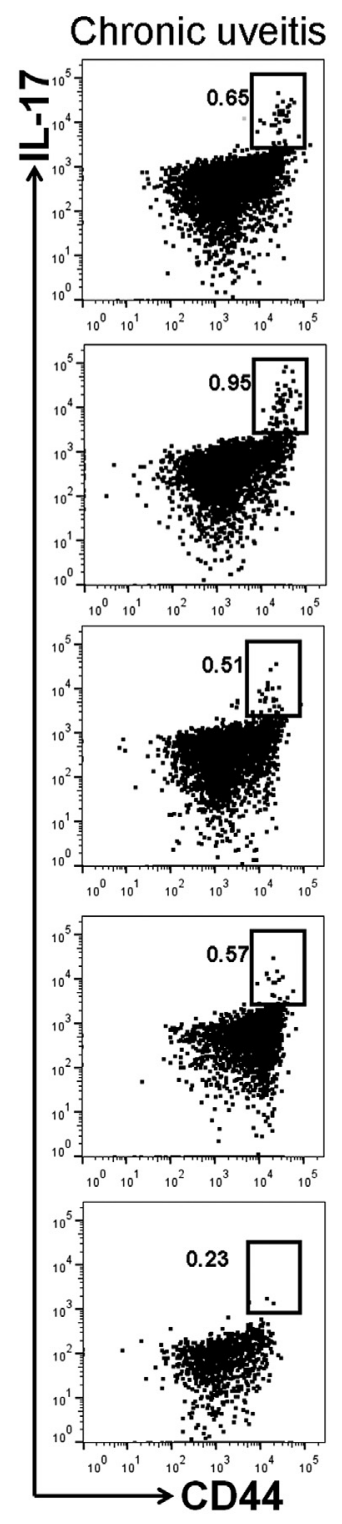
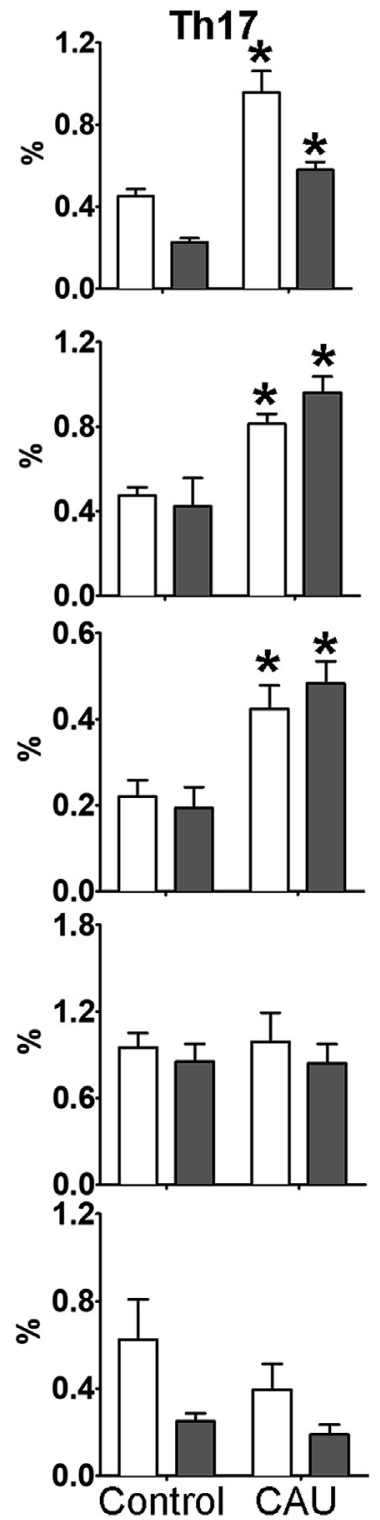
EAU immunization protocol exhibits milder disease during the acute phase (ie, clinical disease score of $<2$ at 3 weeks after immunization), yet has a chronic low-grade inflammation that persists for several months. The authors differentiate this chronic uveitis from the monophasic acute inflammatory response exhibited by most mice (approximately $75 \%$ ). This observation suggested to us that induction of a less vigorous initial immune response may in turn provoke a chronic inflammatory state. Accordingly, an immunization protocol was developed with a lower dose of human IRBP (residues 161 to 180) in B10.RIII strain to develop CAU. Interestingly, the pattern of chronic inflammation reported by Chen et $\mathrm{al}^{15}$ is substantially different from our model. In contrast to the slow onset and gradual disease progression observed following our immunization protocol, the authors describe chronic uveitis mice as having a disease peak at week 3 after immunization (the same time point as the monophasic acute inflammatory group) before returning to a baseline disease severity score of $<1$ that persists in the long-term. The disease peak in our models occurs at week 11 after immunization, with much higher disease scores observed ( $>3$ in the B10.RIII strain) (Figure 1). Moreover, all B10.RIII mice employed in our study developed CAU.

Chronic uveitis has also been reported in studies using the C57BL/6 mouse strain. ${ }^{16,17}$ Similar to our approach of provoking a milder initial immune response in the B10.RIII strain than is typical in EAU models, Caspi RR's immunization protocol combined low-dose pathogenic human IRBP (residues 1 to 20) epitope with a much less pathogenic human IRBP (residues 161 to 180) epitope, instead of pairing the two highly pathogenic epitopes [human IRBP (residues 1 to 20) and whole bovine IRBP protein] commonly used in C57BL/6 EAU induction. ${ }^{32}$ Immunization of C57BL/6 mice according to the conventional EAU protocol has previously been observed to induce chronic uveitis, although the incidence of this occurrence is not clear. ${ }^{37}$ The disease progression pattern in the above study was distinct from our CAU model, but similar to the established EAU pattern showing disease peak at week 3 to 4 after immunization followed by rapid decline. ${ }^{37}$ Although with multiple white lesions, the appearance of the retina in the chronic stage of this study was similar to our model, it was characterized by more dramatic atrophy, vascular changes, and scars. ${ }^{37}$ These differences are likely due to the higher pathogenicity of epitopes employed. ${ }^{37}$ Of note, our study is the first to describe the kinetics of disease progression in the C57BL/6 strain.
In addition to wild-type animal models, the spontaneous development of autoimmune uveitis in transgenic mice has been described. $\mathrm{R} 161 \mathrm{H}$ mice [which express a transgenic $\mathrm{T}$ cell receptor specific to IRBP (residues 161 to 180)] and Aire $^{-1-}$ mice [which are deficient in the autoimmune regulator (Aire)] both demonstrate chronic progressive autoimmune uveitis that is similar to that observed in our models. ${ }^{15,36}$ However, particular caution needs to be taken when using transgenic mouse tools, because many unwanted or unknown effects may exist secondary to gene manipulations. For example, in addition to chronic uveitis, $\mathrm{R} 161 \mathrm{H}$ mice develop cataracts that hinder fundoscopic examination. ${ }^{15}$ Aire ${ }^{-/-}$mice develop multi-organ autoimmune disorders in addition to uveitis, and have limited lifespans relative to wild-type animals. ${ }^{38}$ Most importantly, it can be challenging to translate findings from these relatively artificial models to humans, because human autoimmune uveitis does not occur secondary to these gene mutations.

Both IFN- $\gamma$ - and IL-17-producing $\mathrm{CD}^{+} \mathrm{T}$ cells have been shown to be increased in retinal tissues and to mediate the acute inflammation observed in EAU. ${ }^{8,9,21}$ A prominent infiltration of IL-17-producing Th17 cells into the retina in the chronic form of autoimmune uveitis was detected in our models of CAU. These Th17 cells were further characterized as predominant $\mathrm{CD} 44^{\mathrm{hi}} \mathrm{IL}-17^{+} \mathrm{CD} 4{ }^{+}$ memory Th17 cells, in contrast to the dominant CD $44^{\text {low }}$ effector Th17 cells in acute uveitis, suggesting that these long-lived memory Th17 cells may be driving the chronic intraocular inflammation observed in CAU. Oh et $\mathrm{al}^{17}$ have previously shown that adoptive transfer of cells isolated from the bone marrow of mice with chronic uveitis into naïve mice, after ex vivo stimulation with IRBP, results in development of uveitis in the naïve recipients. The authors concluded that memory $\mathrm{CD}^{+} \mathrm{T}$ cells mediate the transferred disease. Given that the investigators transferred total bone marrow cells (including many immune cells other than $\mathrm{CD}^{+} \mathrm{T}$ cells), we believe that this conclusion is not adequately supported by data. Moreover, the ex vivo stimulation with IRBP has the effect of converting any memory $\mathrm{T}$ cells specific to IRBP into effector cells, so the investigators likely transferred effector rather than memory cells. ${ }^{17}$ In the same report, the authors did not characterize specific T-cell lineages or memory phenotypes in their study. Evidently, further work is required to demonstrate the direct pathogenic role of memory Th17 cells in mediating chronic uveitis. In our work, for the first time, we demonstrate the presence of IL$7 \mathrm{R}^{+} \mathrm{IL}-15 \mathrm{R}^{+} \mathrm{CD} 44^{\mathrm{hi}} \mathrm{IL}-17^{+} \mathrm{CD} 4^{+}$memory Th17 cells in

\footnotetext{
Figure 7 Memory T-helper 17 (Th17) response in lymphoid tissues in C57BL/6 mice with chronic autoimmune uveitis (CAU). Cervical draining lymph node (CLN), distal inguinal LN (ILN), spleen, bone marrow, and peripheral blood samples were collected and prepared for flow cytometric assessment at week 12. A: Gating strategy and isotype controls for analyzing total and memory Th17 cells. B: Representative flow cytometry histograms show the expression of IL-7R and IL-15R on CD44 ${ }^{\text {hi }}$ Th17 cells. Results are from a single experiment and are representative of two performed. C: Frequencies of IL17 $7^{+}$IFN- $\gamma^{-}$CD4 ${ }^{+}$(total Th17, white bars) and $\mathrm{CD} 44^{\mathrm{hi}} \mathrm{IL}-17^{+} \mathrm{CD}^{+}$(memory Th17, gray bars) cells among total CD4 ${ }^{+}$T cells were examined with representative flow cytometry dot plots shown on the left, and bar charts summarizing total and memory Th17 cells shown on the far right. $n=3$ to 4 per group (B). ${ }^{*} P<0.05$ versus control. FSC, forward scatter; IFN- $\gamma$, interferon- $\gamma$.
} 
chronic uveitis by direct characterization of the $\mathrm{CD}^{+} \mathrm{T}$ cells to establish their activation versus memory status.

Our study has established unique mouse models of chronic autoimmune uveitis, which recapitulate key features of chronic human disease, and manifest as gradually progressive intraocular inflammation. We directly characterize a distinct memory Th17 cell population in both the retina and peripheral lymphoid compartments in these models. Further investigation of the pathogenic role that Th17mediated immunologic memory plays in maintaining the chronicity of uveitis may provide valuable insights for the development of novel therapeutic approaches.

\section{Acknowledgment}

N.-W.F. thanks the Yin Shu-Tien Foundation for support through the Taipei Veterans General Hospital-National Yang-Ming University Excellent Physician Scientists Cultivation Program.

\section{Supplemental Data}

Supplemental material for this article can be found at http://doi.org/10.1016/j.ajpath.2020.09.004.

\section{References}

1. Sheu SJ, Chen SC: Recent advances in managing and understanding uveitis. F1000Res 2017, 6:280

2. Nussenblatt RB: The natural history of uveitis. Int Ophthalmol 1990, 14:303-308

3. Acharya NR, Tham VM, Esterberg E, Borkar DS, Parker JV, Vinoya AC, Uchida A: Incidence and prevalence of uveitis: results from the Pacific Ocular Inflammation Study. JAMA Ophthalmol 2013, 131:1405-1412

4. Goldstein H: The reported demography and causes of blindness throughout the world. Adv Ophthalmol 1980, 40:1-99

5. Darrell RW, Wagener HP, Kurland LT: Epidemiology of uveitis: incidence and prevalence in a small urban community. Arch Ophthalmol 1962, 68:502-514

6. Suttorp-Schulten MSA, Rothova A: The possible impact of uveitis in blindness: a literature survey. Br J Ophthalmol 1996, 80:844-848

7. McCluskey PJ, Towler HMA, Lightman S: Regular review: management of chronic uveitis. Br Med J 2000, 320:555-558

8. Caspi RR: Understanding autoimmune uveitis through animal models: the friedenwald lecture. Invest Ophthalmol Vis Sci 2011, 52: $1873-1879$

9. Amadi-Obi A, Yu CR, Liu X, Mahdi RM, Clarke GL, Nussenblatt RB, Gery I, Lee YS, Egwuagu CE: TH17 cells contribute to uveitis and scleritis and are expanded by IL-2 and inhibited by IL-27/STAT1. Nat Med 2007, 13:711-718

10. Eskandarpour M, Alexander R, Adamson P, Calder VL: Pharmacological inhibition of bromodomain proteins suppresses retinal inflammatory disease and downregulates retinal Th17 cells. J Immunol 2017, 198:1093-1103

11. Durrani OM, Meads CA, Murray PI, Uveitis: A potentially blinding disease. Ophthalmologica 2004, 218:223-236

12. Lin W, Buscher K, Wang B, Fan Z, Song N, Li P, Yue Y, Li B, Li C, Bi H: Soluble CD83 alleviates experimental autoimmune uveitis by inhibiting filamentous actin-dependent calcium release in dendritic cells. Front Immunol 2018, 9:1567

13. Lin W, Man X, Li P, Song N, Yue Y, Li B, Li Y, Sun Y, Fu Q: NK cells are negatively regulated by $\mathrm{SCD} 83$ in experimental autoimmune uveitis. Sci Rep 2017, 7:12895

14. Ke Y, Liu K, Huang G-Q, Cui Y, Kaplan HJ, Shao H, Sun D: Antiinflammatory role of IL-17 in experimental autoimmune uveitis. J Immunol 2009, 182:3183-3190

15. Chen J, Qian H, Horai R, Chan CC, Falick Y, Caspi RR: Comparative analysis of induced vs. spontaneous models of autoimmune uveitis targeting the interphotoreceptor retinoid binding protein. PLoS One 2013, 8:e72161

16. Xu H, Koch P, Chen M, Lau A, Reid DM, Forrester JV: A clinical grading system for retinal inflammation in the chronic model of experimental autoimmune uveoretinitis using digital fundus images. Exp Eye Res 2008, 87:319-326

17. Oh H-M, Yu C-R, Lee Y, Chan C-C, Maminishkis A, Egwuagu CE: Autoreactive memory CD4 $+\mathrm{T}$ lymphocytes that mediate chronic uveitis reside in the bone marrow through STAT3-dependent mechanisms. J Immunol 2011, 187:3338-3346

18. Raverdeau M, Christofi M, Malara A, Wilk MM, Misiak A, Kuffova L, Yu T, McGinley AM, Quinn SM, Massilamany C, Reddy J, Forrester JV, Mills KH: Retinoic acid-induced autoantigenspecific type 1 regulatory T cells suppress autoimmunity. EMBO Rep 2019, 20:e47121

19. Li J, Ren J, Yip YWY, Zhang X, Chu KO, Ng TK, Chan SO, Pang CP, Chu WK: Quantitative characterization of autoimmune uveoretinitis in an experimental mouse model. Invest Ophthalmol Vis Sci 2017, 58:4193-4200

20. Chen Y, Chauhan SK, Shao C, Omoto M, Inomata T, Dana R: IFN$\gamma$-expressing Th17 cells are required for development of severe ocular surface autoimmunity. J Immunol 2017, 199:1163-1169

21. Luger D, Silver PB, Tang J, Cua D, Chen Z, Iwakura Y, Bowman EP, Sgambellone NM, Chan CC, Caspi RR: Either a Th17 or a Th1 effector response can drive autoimmunity: conditions of disease induction affect dominant effector category. J Exp Med 2008, 205:799-810

22. Sallusto F, Geginat J, Lanzavecchia A: Central memory and effector memory T cell subsets: function, generation, and maintenance. Annu Rev Immunol 2004, 22:745-763

23. Chen Y, Chauhan SK, Soo Lee H, Saban DR, Dana R: Chronic dry eye disease is principally mediated by effector memory Th17 cells. Mucosal Immunol 2014, 7:38-45

24. Haines CJ, Chen Y, Blumenschein WM, Jain R, Chang C, JoyceShaikh B, Porth K, Boniface K, Mattson J, Basham B, Anderton SM, McClanahan TK, Sadekova S, Cua DJ, McGeachy MJ: Autoimmune memory $\mathrm{T}$ helper 17 cell function and expansion are dependent on interleukin-23. Cell Rep 2013, 3:1378-1388

25. Mueller SN, Gebhardt T, Carbone FR, Heath WR: Memory T cell subsets, migration patterns, and tissue residence. Annu Rev Immunol 2013, 31:137-161

26. Kryczek I, Zhao E, Liu Y, Wang Y, Vatan L, Szeliga W, Moyer J, Klimczak A, Lange A, Zou W: Human TH17 cells are long-lived effector memory cells. Sci Transl Med 2011, 3:104ra100

27. Nemoto Y, Kanai T, Kameyama K, Shinohara T, Sakamoto N, Totsuka T, Okamoto R, Tsuchiya K, Nakamura T, Sudo T, Matsumoto S, Watanabe M: Long-lived colitogenic CD4 + memory $\mathrm{T}$ cells residing outside the intestine participate in the perpetuation of chronic colitis. J Immunol 2009, 183:5059-5068

28. Zhang L, Wan F, Song J, Tang K, Zheng F, Guo J, Guo D, Bi H: Imbalance between Th17 cells and regulatory T cells during monophasic experimental autoimmune uveitis. Inflammation 2016, 39:113-122

29. Chen Y, Chauhan SK, Tan X, Dana R: Interleukin-7 and -15 maintain pathogenic memory Th17 cells in autoimmunity. J Autoimmun 2017, 77:96-103

30. Seddon B, Tomlinson P, Zamoyska R: Interleukin 7 and $\mathrm{T}$ cell receptor signals regulate homeostasis of CD4 memory cells. Nat Immunol 2003, 4:680-686 
31. Nakayama T, Yamashita M: Critical role of the Polycomb and Trithorax complexes in the maintenance of CD4 T cell memory. Semin Immunol 2009, 21:78-83

32. Caspi RR: Experimental autoimmune uveoretinitis in the rat and mouse. Curr Protoc Immunol 2003, 53:15.6.1-15.6.20

33. Yang H, Zheng S, Qiu Y, Yang Y, Wang C, Yang P, Li Q, Lei B: Activation of liver $\mathrm{X}$ receptor alleviates ocular inflammation in experimental autoimmune uveitis. Invest Ophthalmol Vis Sci 2014, 55: 2795-2804

34. Agarwal RK, Silver PB, Caspi RR: Rodent models of experimental autoimmune uveitis. Methods Mol Biol 2012, 900: 443-469

35. Takeda A, Hasegawa E, Fukuhara T, Hirakawa S, Yamada H, Yang Y, Yoshimura T, Hisatomi T, Oshima Y, Yoshida H, Sonoda KH, Ishibashi T: EBI3 is pivotal for the initiation of experimental autoimmune uveitis. Exp Eye Res 2014, 125: $107-113$

36. Horai R, Silver PB, Chen J, Agarwal RK, Chong WP, Jittayasothorn Y, Mattapallil MJ, Nguyen S, Natarajan K, Villasmil R, Wang P, Karabekian Z, Lytton SD, Chan CC, Caspi RR: Breakdown of immune privilege and spontaneous autoimmunity in mice expressing a transgenic $\mathrm{T}$ cell receptor specific for a retinal autoantigen. J Autoimmun 2013, 44:21-33

37. Chen M, Copland DA, Zhao J, Liu J, Forrester JV, Dick AD, Xu H: Persistent inflammation subverts thrombospondin-1induced regulation of retinal angiogenesis and is driven by CCR2 ligation. Am J Pathol 2012, 180:235-245

38. Gray DHD, Gavanescu I, Benoist C, Mathis D: Danger-free autoimmune disease in Aire-deficient mice. Proc Natl Acad Sci U S A 2007, 104:18193-18198 